\title{
BREVE ANÁLISE DOS INTERESSES E CONTRADIÇÕES AO LONGO DA POLÍTICA CRIMINAL DE DROGAS NO BRASIL
}

\section{Rafael Bulgakov Klock Rodrigues ${ }^{1}$ Luiz Fernando Kazmierczak ${ }^{2}$}

RESUMO: O presente artigo visa demonstrar que a Política Criminal de Drogas no Brasil carece de racionalidade, seja pela apropriação das políticas exteriores, por desapego à realidade ou por propósito dos legisladores. Analisou-se todas as legislações brasileiras acerca da temática partindo do Código Penal de 1890 até o Pacote Anticrime. O método utilizado foi o dialético, contestando a (in)validade das legislações frente aos fatos. Utilizou-se fontes históricas, identificando os acontecimentos que marcaram essas políticas, e documentais, partindo da análise das legislações e atas taquigráficas legislativas. Concluiu-se que as legislações de drogas continuam cercadas de subjetividades e incongruências.

PALAVRAS-CHAVE: Política de drogas. Processo legislativo. Internação compulsória. Pacote Anticrime. Leis inválidas.

\section{BRIEF ANALYSIS OF INTERESTS AND CONTRADICTIONS THROUGH CRIMINAL DRUG POLICY IN BRAZIL}

\begin{abstract}
This article aims to demonstrate that the Criminal Drug Policy in Brazil lacks rationality, either through the appropriation of foreign policies, through detachment from reality, or legislative purposes. All Brazilian legislation about drugs was analyzed starting from the Penal Code of 1890 up to the Anti-Crime Package. The method used was the dialectic, contesting the (in) validity of the legislation in face of the facts. Historical sources were used, identifying the events that marked these policies, and documental, based on the analysis of legislation and legislative shorthand minutes. It was concluded that drug laws remain surrounded by subjectivities and incongruities.
\end{abstract}

KEYWORDS: Drug policy. Legislative process. Compulsory hospitalization. Anti-Crime Package. Invalid laws.

\section{INTRODUÇÃO}

A lei de drogas (BRASIL, 2006) é a segunda maior responsável pelo encarceramento em massa no Brasil, ficando apenas atrás do roubo. Sob o pretexto de tutelar o bem jurídico "saúde

\footnotetext{
${ }^{1}$ Mestrando em Ciência Jurídica na Universidade Estadual do Norte do Paranã (UENP) e graduando em Licenciatura em História (UNIGRAN). Email: rafael_klock@ hotmail.com.

${ }^{2}$ Doutor em Direito Penal pela Pontifícia Universidade Católica de São Paulo (PUC/SP), e Professor Adjunto na disciplina de Direito Penal na Universidade Estadual do Norte do Paraná (UENP), onde exerce o cargo de Diretor do Centro de Ciências Sociais Aplicadas do Campus de Jacarezinho. Email: lfkaz@uenp.edu.br.
} 
pública", a Lei n ${ }^{\circ}$ 11.343/2006 mantém cerca de 148.988 pessoas presas (CNJ; BNMP, 2018, p. 47). Todavia, será que o crime tipificado como tráfico é responsável por essa lesão? Para identificar essa suposta capacidade dano, deve-se ter em mente quais são os bens jurídicos afetados, no que consiste o tráfico e quem é o traficante.

Conforme Érika Mendes CARVALHO e Gustavo Noronha de ÁVILA (2016, p. 146) citando a crítica de Luis Greco, reconhece-se

'a criticabilidade da proibição, que tutela um bem jurídico individual mesmo contra a vontade de seu titular' e, além disso, deslegitimarmos a absurda sanção cominada, 'pois se o tráfico de tóxico nada mais é do que uma conduta que gera um perigo abstrato de lesão à integridade física, essa conduta não pode sofrer pena mais grave do que a do respectivo crime de lesão, no caso de lesões corporais'

No tocante ao conceito de tráfico, Luís Carlos VALOIS (2017, p. 536) afirma que a "única diferença entre a conduta do traficante e a de um comerciante qualquer é a criminalização de seu comércio", já que a "relação comercial entre traficante e viciado é voluntária e indiferente como são todas as outras". Assim, o pretenso bem "saúde pública" não parece tão ofendido.

Por sua vez, Orlando Zaccone (D’ELIA FILHO, 2011, p. 12) identificou que a maior parte dos "traficantes" são homens e mulheres pobres e de baixa escolaridade, negros, e que não portavam armas no momento dos respectivos flagrantes.

Frente a esses argumentos, e visualizando que da lei de drogas de 1971 para a de 1976 a pena mínima cominada ao tráfico triplicou e a pena máxima mais que duplicou, aparentemente sem fundamentação científica, questiona-se: onde está a lesão do referido tipo penal e será que os usuários são realmente os lesados?

Dessa maneira, a problemática da presente pesquisa é: o percurso da Política Criminal de Drogas no Brasil é coerente com a realidade? Tendo por hipótese que esta, de fato, carece de racionalidade, seja pela apropriação das políticas de outros países - principalmente EUA -, seja por desapego à realidade, ou por interesses desconhecidos, o trabalho se propõe a apontar incongruências e subjetividades que cercam a construção das políticas criminais de drogas no Brasil e demonstrar as incoerências dos legisladores frente à temática “drogas”.

Para alcançar estes objetivos, o método a ser utilizado é o dialético, de forma a contestar a validade das referidas legislações frente ao contexto das épocas, e para isso serão utilizadas 
fontes históricas, vez que é necessário indicar o encadeamento dos fatos que marcaram a construção dessas políticas, e fontes documentais, considerando a análise de textos legislativos e de atas taquigráficas das casas legislativas.

Por fim, o marco temporal escolhido para revisão são as legislações pertinentes à política criminal de drogas no Brasil, a partir do Código Penal de 1890 - Decreto n. 847, de 11 de outubro de 1890 - até o Pacote Anticrime - Lei n. 13.964, de 24 de dezembro de 2019.

\section{Escorço histórico da legislação nacional de drogas}

A partir desse tópico será realizada a revisão da legislação brasileira acerca da política de drogas, divida, a priori, em quatro fases históricas, a primeira com raízes na legislação criminal portuguesa, que deu origem ao Código Penal de 1890. A segunda, veio junta com a ratificação de Tratados Internacionais, sendo estes muito influenciados pelos EUA, entre 1921 e 1967. A terceira, abarcando todo o período de Ditadura Militar no Brasil, demonstrando um endurecimento das legislações, e o quarto, com a redemocratização brasileira, onde se esperava legislações mais avançadas. O que não ocorreu.

\subsection{Primeira fase: 1890 - 1920}

O Código Penal de 1890, publicado em 11 de outubro do mesmo ano, trazia condutas próximas ao tráfico de drogas, como este é conhecido atualmente, nos seus artigos 159, 396, 397 e 398, em seus caput, da seguinte forma:

Art. 159. Expôr á venda, ou ministrar, substancias venenosas, sem legitima autorização e sem as formalidades prescriptas nos regulamentos sanitarios:

Art. 396. Embriagar-se por habito, ou apresentar-se em publico em estado de embriaguez manifesta:

Art. 397. Fornecer a alguem, em logar frequentado pelo publico, bebidas com o fim de embriagal-o, ou de augmentar-lhe a embriaguez:

Art. 398. Si o infractor for dono de casa de vender bebidas, ou substancias inebriantes: [...] (BRASIL, 1890).

Por sua vez, seus preceitos secundários previam penas de prisão de quinze dias a seis meses, e multas de $200 \$$ a $500 \$ 000$ (mil réis). 
Tal código é fruto de um projeto feito em apenas três meses pelo Conselheiro Baptista Pereira, à pedido do Ministro Campos Sales (ZAFFARONI; PIERANGELI, 2002, p. 218), "reconhecendo a urgente necessidade de reformar o regimen penal", dada à Proclamação da República ocorrida em 1889.

O termo "droga" ainda não estava cunhado ao tempo da legislação. Em seu lugar, usavase "substancias venenosas", com seu conceito definido no parágrafo único do artigo 296 da mesma legislação, sendo "toda substancia mineral ou organica, que ingerida no organismo ou applicada ao seu exterior, sendo observada, determine a morte, ponha em perigo a vida, ou altere profundamente a saúde" (BRASIL, 1890).

\title{
2.2 Segunda fase: 1921 - 1967
}

Em 6 de julho de 1921, é publicado o Decreto n. 4.294, prevendo "penalidades para os contraventores na venda de cocaina, opio, morphina e seus derivados".

O Decreto revogou os artigos 159, 396, 397 e 398, do Código Penal de 1890, e trouxe em seus artigos $1^{\circ}, 2^{\circ}, 3^{\circ}$ e $4^{\circ}$, tipos muito semelhantes àqueles, com a ressalva de, punir muito mais severamente, o fato de a substancia ter qualidade entorpecente, "como o opio e seus derivados; cocaina e seus derivados", com pena de um a quatro anos, conforme parágrafo único de seu artigo $1^{\circ}$ (BRASIL, 1921).

Tal legislação foi promulgada pelo Presidente Epitácio Pessoa. A proibição do ópio e seus derivados chama atenção, principalmente, pelo fato de tal substância ter sido considerada como medicamento até 1912, e mais ainda por quase ter tido comércio no Brasil, mostrando claramente a influência internacional que a legislação sofreu.

Em 11 de Janeiro de 1932 era publicado o Decreto n. 20.930, com o intuito de fiscalizar o "emprego e o comércio das substâncias tóxicas entorpecentes", conforme acordado com o “Comité Central Permanente do Opio da Liga das Nações”. Esse comitê foi criado na Segunda Convenção Internacional do Ópio, de 1925.

Tal Decreto foi assinado durante o primeiro governo do Presidente Getúlio Vargas, um pouco antes da aprovação da Consolidação das Leis Penais - Decreto n. 22.213/1932 -, escrita pelo Desembargador Vicente Piragibe.

\author{
Rev. de Criminologias e Políticas Criminais | e-ISSN: 2526-0065 | Evento Virtual | v. 6 | n. 1 | \\ p. 41-62 | Jan/Jun. 2020


O artigo $1^{\circ}$ dessa lei já ampliava o rol de substâncias entorpecentes, sobrelevando-se ainda a proibição da folha de coca, que tem sua origem na América Latina, e era muito consumida pelos povos originários.

O Decreto previa em seu artigo 25 pena de um a cinco ano, além de multa, para quem

Vender, ministrar, dar, trocar, ceder, ou, de qualquer modo, proporcionar substâncias entorpecentes; propor-se a qualquer desses atos sem as formalidades prescritas no presente decreto; induzir, ou instigar, por atos ou por palavras, o uso de quaisquer dessas substâncias. (BRASIL, 1932a)

Sucedeu-se então, o Decreto n. 22.213/1932, denominado de "Consolidação das Leis Penaes" tratou da publicação de uma interpretação particular do Código Penal de 1890, feita pelo Desembargador Vicente Piragibe. Na aplicação do artigo 159 daquela Lei, o Desembargador já trazia a necessidade de se atentar às "formalidades prescriptas pelo Departamento Nacional de Saude Publica", como uma norma penal em branco que se tornou. Impressionante é ver que em seu parágrafo primeiro, Piragibe previa a possibilidade de "dóse superior á therapeutica determinada" (BRASIL, 1932b), discurso esse que já ganhava força nos Estados Unidos da América, como forma de criminalização dos médicos que prescreviam substâncias com efeito entorpecente.

Nessa esteira legislativa, em 25 de novembro de 1938, foi publicado o Decreto n. 891, vigendo a Lei de Fiscalização de Entorpecentes. Legislação fruto do Estado Novo de Vargas, amplia significativamente em seu artigo primeiro, o rol de substâncias consideradas entorpecentes.

Coincidentemente, o tráfico de drogas é previsto em seu artigo 33, assim como a legislação atual. A pena continua sendo análoga à lei anterior, com o máximo de 5 anos (BRASIL, 1938).

Em 7 de dezembro de 1940 é publicado o Decreto-lei n. 2.848, o Código Penal que vige até hodiernamente - todavia, com sua parte geral completamente reformada e parte especial significativamente alterada -, prevendo no artigo 281 o crime de tráfico de drogas, com pena entre um e cinco anos, entretanto, com o número de verbos que compõem o tipo devidamente ampliado (BRASIL, 1940). 
Por se tratar de um período ditatorial que foi o "Estado Novo", marcado por uma série de limitações às liberdades individuais, é de se impressionar o não recrudescimento da pena de tal delito. Talvez fruto da sapiência dos envolvidos no projeto de lei, como Nélson Hungria e Roberto Lyra (ZAFFARONI; PIERANGELI, 2002, p. 222).

Voltando a acompanhar a acompanhar o Direito Internacional, em 27 de agosto de 1964 é promulgado pelo governo de Castello Branco a Convenção Única de Entorpecentes, assinada em Nova York no ano de 1961. O período de sua promulgação é conhecido por ser os primeiros meses de ditadura militar no Brasil, momento marcada pela luta "anticomunista" e pela influência estadunidense nas legislações.

Chama atenção já no preâmbulo da convenção a frase "Preocupadas com a saúde física e moral da humanidade". Situação que remete ao pensamento de Howard BECKER (2008, p. 153/154), quando este descreve os empreendedores morais, como sendo aqueles indivíduos tratam a busca de suas ideologias como uma cruzada, acreditando piamente em sua superioridade ética, e com o fim de torná-la valor universal.

Além disso, a convenção traz em seu artigo 36, parágrafo primeiro, a obrigação dos Estados-parte de tratar o tráfico de drogas como infrações graves, e que ainda devem ser "castigadas de forma adequada, especialmente com pena prisão ou outras de privação a liberdade". Tal passagem evidencia diversos aspectos do Direito naquele momento histórico: $1^{\circ}$ ) quando se fala em castigar, denota-se o caráter meramente retributiva da pena, sem considerar a natureza ressocializadora desta; $2^{\circ}$ ) trazendo que a punição deve ser "especialmente com pena prisão" (sic), mostra-se a desconsideração com o princípio da individualização da pena, que mesmo não estando cunhado à época, já era evidente por conta da própria lógica jurídica.

Além disso, a alínea "a" do parágrafo segundo deste mesmo artigo traz que "casa delito enumerado no parágrafo 1 , ser fôr cometido em diferente países será considerado um delíto distinto"(sic), incorrendo logicamente em bis in idem, criminalizando o que seriam, até então, fases preparatórias do crime (BRASIL, 1964).

Por fim, interessante notar que no artigo 49, parágrafo primeiro, há previsão dos Estados autorizarem temporariamente, "o uso do ópio para fumar"; "a mastigação da fôlha de coca"; e "o uso de canabis, da resina da canabis, de extrato e tinturas de canabis, com finalidade não médicas", de forma a rever proibição trazida na Primeira Convenção Internacional do Ópio.

\section{Rev. de Criminologias e Políticas Criminais | e-ISSN: 2526-0065 | Evento Virtual | v. 6 | n. 1 | p. 41-62 | Jan/Jun. 2020


Talvez por perceberem que proibir comportamentos milenares seja aberrante, ou talvez por mera liberalidade.

\subsection{Terceira fase: 1968 - 1987}

Veio o Decreto-Lei 385/1968, datando de 26 de dezembro, que alterava novamente o artigo 281 do Código Penal de 1940, mantendo a mesma pena privativa de liberdade para os casos de tráfico, entretanto, ao invés de determinar valores para a pena de multa, decidiu-se vinculá-la ao salário mínimo vigente, com mínimo de 10 e máximo de 50 salários. Essa mudança provavelmente é fruto da inflação vivida à época da ditadura, vez que a multa anterior poderia se mostrar ínfima ante a correção da moeda (BRASIL, 1968).

Ressalta-se ainda que, fora acrescentado um parágrafo ao artigo, prevendo a punição de médico ou farmacêutico que prescrevesse substâncias "fora dos casos indicados pela terapêutica, ou em dose evidentemente maior que a necessária ou com infração de preceito legal ou regulamentar", limitando ainda mais a atividade médica, sem a devida justificativa, vez que tratamentos médicos são uma atividade-meio, não se sabendo ao certo qual é o medicamento mais apropriado, tampouco a dosagem deste.

Em 29 de outubro de 1971 é publicada a Lei n. 5.726, pelo governo Médici, trazendo a formatação de um sistema de prevenção do tráfico e uso de substâncias entorpecentes, além de rito processual próprio, e ainda modificando novamente o artigo 281 do Código Penal de 1940.

Nesta modificação a pena máxima do delito de tráfico é aumenta para 6 anos, ou seja, 1 ano a mais do que tinha se mantido vigente por mais de trinta anos. Tem-se ainda o enrijecimento da pena de multa, tendo seu valor máximo dobrado e seu valor mínimo, quintuplicado (BRASIL, 1971).

É com a Lei n. 6.368, de 21 de outubro de 1976, que se inaugura a política de droga como conhecemos hoje, publicada pelo Presidente Ernesto Geisel. A lei representa um marco punitivista, revogando o artigo 281 do Código Penal de 1940, e trazendo o tipo de tráfico em seu artigo 12. Dessa vez, a pena para o delito passa a ser de 3 anos a 15 anos (BRASIL, 1976).

Surgiu o Decreto n. 79.388/1977, a Convenção sobre Substâncias Psicotrópicas. Inicialmente, cabe salientar a alteração de um dos bens jurídicos que deixaram de ser tutelados ou foram eufemizados nesta norma. Enquanto a última Convenção Internacional retificada pelo 
Brasil (Decreto n ${ }^{o}$ 54.216/1964) trazia em seu preâmbulo "Preocupadas com a saúde física e moral da humanidade", a nova Convenção aporta "Preocupadas com a saúde e o bem-estar da humanidade" (BRASIL, 1977).

Talvez tenha o legislador tenha relativizado essa "cruzada moralizante", em detrimento de um bem jurídico maior, ou apenas percebido que elencar a "moral" como objeto de proteção, de maneira tão explícita, seja vil.

Tal norma foi grandemente influenciada pela política bélica do Presidente Estadunidense, Richard Nixon, entre 1969 e 1974, afinal, fora este quem afirmou que as drogas eram "o primeiro inimigo público não econômico" (OLMO, 1990, p. 39).

\subsection{Quarta fase: 1988 - 2019}

A Constituição de 1988 representa um retorno democrático ao Estado Brasileiro, entretanto o tráfico de drogas continuava sendo visto como execrável. Isso é percebido no inciso XLII, do artigo $5^{\circ}$, com a seguinte redação:

a lei considerará crimes inafiançáveis e insuscetíveis de graça ou anistia a prática da tortura, o tráfico ilícito de entorpecentes e drogas afins, o terrorismo e os definidos como crimes hediondos, por eles respondendo os mandantes, os executores e os que, podendo evitá-los, se omitirem;

Além disso, tal crime é ressaltado no inciso LI, que trata sobre a possibilidade de extradição, no artigo 144, parágrafo primeiro, inciso II, trazendo como uma das funções da polícia Federal a repressão do tráfico, e no parágrafo único do artigo 243, prevendo que "Todo e qualquer bem de valor econômico apreendido em decorrência do tráfico ilícito de entorpecentes e drogas afins e da exploração de trabalho escravo será confiscado e reverterá a fundo especial com destinação específica".

Análise interessante é a que se pôde fazer da Assembleia Nacional Constituinte da qual se originou esta Constituição.

A publicação do Anteprojeto Constitucional ocorreu em 26 de setembro de 1986, presidida pelo jurista Afonso Arinos, e a Subcomissão dos Direitos e Garantias Individuais, que trata sobre o tráfico de drogas fora relatada por Darcy Pozza. Nesta redação incipiente já era disposto que "Repudiam-se os crimes de tortura e tráfico de drogas. perniciosos e horrendos, 
imputando-os como crimes inafiançáveis, imprescritíveis e inanistiáveis". Noutra passagem é trazido novamente que "a integridade física e mental e a existência digna; a tortura e o tráfico de tóxicos constituem crimes inafiançáveis e insuscetíveis de anistia, substituição ou suspensão da pena, ou livramento condicional, ou prescrição, na forma da lei” (ASSEMBLÉIA NACIONAL CONSTITUINTE, 1987a, p. 6/8).

Em 15 de maio de 1987, o constituinte José Genoino Neto, representando o Partido dos Trabalhadores, apresenta emenda ao Anteprojeto, o seguinte texto: "É crime a produção de drogas para fins comerciais, bem como o seu tráfico. PARÁGRAFO ÚNICO: A lei não punirá criminalmente o consumo individual de drogas".

Alega que o "consumo individual de drogas, que é uma questão de consciência pessoal e de concepção existencial, a qual não pode ser tratada como mero caso de polícia e de prisão, o que vale também para o alcoolismo e o tabagismo". Além disso, também traz a possibilidade de plantio pessoal pelo próprio consumidor, dizendo que essa medida "já vem sendo adotada em países capitalistas desenvolvidos”.

Por outro lado, em outra emenda o mesmo constituinte diz que lei ordinária não poderia "revogá-los, diminuí-los ou discipliná-los" em relação ao crime de tráfico de drogas, sob o risco de anular as garantias constitucionais (ASSEMBLÉIA NACIONAL CONSTITUINTE, 1987b, p. 86).

O constituinte Eliel Rodrigues, por sua vez, traz como justificação, em 16 de maio de 1987, que “os crimes de assalto à mão armada. os de mando e a produção de drogas. porquanto se tratam de crimes hediondos, especialmente o relativo a tóxicos, que estão afetando as operações futuras. Os jovens são as vítimas por excelência desses criminosos. A punição, tanto para quem produz, como para quem trafica, deve ter o maior rigor possível" (ASSEMBLÉIA NACIONAL CONSTITUINTE, 1987b, p. 106).

Em um lampejo de sobriedade, o constituinte Nyder Barbosa, do PMDB, apresentou emenda em 17 de maio de 1987, com o intuito de suprimir o tráfico de tóxicos daquele artigo, justificando que

\footnotetext{
"Não podemos compreender a pretensão do legislador Constituinte que quer equiparar o
} crime nefando de tortura ao crime comum de tráfico de tóxicos. 
A alegação de que o tráfico de tóxicos atenta contra a dignidade da pessoa humana não procede, data venia.- A proceder, seria o caso de incluir-se neste dispositivo outros tipos de crimes que atentam contra a honra do ser humano como, por exemplo: o estupro, o sequestro, a calúnia, a difamação, dentre outros.-" (ASSEMBLÉIA NACIONAL CONSTITUINTE, 1987b, p. 166).

No mesmo sentido, o constituinte Haroldo Lima, em 18 de maio de 1987, pediu pela retirada do delito de tráfico, justificando que "Não se deve misturar um crime como o tráfico de tóxicos com o bárbaro crime de tortura, considerando ambos como inafiançáveis e insuscetíveis de anistia. Na nossa opinião, o tráfico de tóxicos deve ser matéria abordada na legislação ordinária” (ASSEMBLÉIA NACIONAL CONSTITUINTE, 1987b, p. 229).

Em outro sentido, temos a proposta de emenda da Deputada Lúcia Braga, do PFL, em 08 de junho de 1987, afirmando que

A Constituição que estamos elaborando não pode ser omissa em relação a problema de tão graves proporções - a produção e o tráfico de tóxicos, pela dependência criada nas pessoas que deles fazem uso constante, pelos efeitos perniciosos e atentatórios à integridade física e mental do ser humano (ASSEMBLÉIA NACIONAL CONSTITUINTE, 1987c, p. 4).

E ainda, do próprio relator desta Subcomissão, Darcy Pozza, do PDS, que em 09 do junho de 1987, em relação as drogas, ratificou sua emenda, sob o pretexto de que "A juventude brasileira é a que mais sofre as conseqüências danosas dos seus efeitos. Por outro lado, é sabido que a maioria dos crimes odiendos são praticados sob efeito de alucinógenos” (ASSEMBLÉIA NACIONAL CONSTITUINTE, 1987c, p. 24). Dentre todas as emendas opostas, restou aprovada a de autoria do constituinte Eliel Rodrigues.

Com a Lei n. 8.072/1990, temos o tráfico como crime hediondo. João Gualberto Garcez RAMOS (1991, p. 40) cita um testemunho de Miguel Reale Júnior, que em programa televisivo, afirmou que a classificação de crimes hediondos

nasceu de um acordo político do Partido do Movimento Democrático Brasileiro (PMDB) com um constituinte que comandava um número considerável de constituintes. Segundo o referido acordo, em troca da aprovação da expressão 'crimes hediondos', desejada por esse constituinte e seus comandados, o PMDB teria votos necessários para a aprovação de um determinado direito social. 
O Instituto Latino Americano das Nações Unidas para Prevenção do Delito e Tratamento do delinquente - ILANUD/Brasil, no mesmo sentido, colheu depoimento de diversos legisladores durante a tramitação da lei, alegando que gostariam de ter mais tempo para analisar a legislação, e ainda que esta tinha sido mal elaborada e às pressas (VALOIS, 2017, p. 441/442).

Veio então o Decreto n. 154/1991, como a Convenção Contra o Tráfico Ilícito de Entorpecentes e Substâncias Psicotrópicas. Sendo este o último Tratado Internacional sobre entorpecentes que ocorreu, e que fora ratificado pelo Brasil, ele se demonstra muito mais condizente à realidade que seus antecessores, principalmente quando, em seu artigo $3^{\circ}$, parágrafo $4^{\circ}$, alínea "a" traz que "Cada uma das Partes disporá que, pela prática dos delitos estabelecidos no parágrafo I deste Artigo, se apliquem sanções proporcionais à gravidade dos delitos, tais como a pena de prisão, ou outras formas de privação de liberdade, sanções pecuniárias e o confisco".

Ou seja, a partir deste momento a Convenção passa a prever penas alternativas à de prisão, contrariando o prescrito na Lei n. 8.072/1990. Entretanto, ainda permanece criminalizada a posse de drogas para consumo próprio, conforme artigo $3^{\circ}$, parágrafo $2^{\circ}$.

Retornando à legislação brasileira, em 11 de janeiro de 2002, é publicada a Lei n. 10.409. Esperava-se que essa lei representasse uma nova política de drogas frente a um regime democrático, afinal, tal projeto fora apresentado à Câmara dos Deputados em 18 de setembro de 1991, pelo Deputado Elias Murad, do PSDB/MG. Ledo engano. Tal norma estava repleta de inconsistências que fizeram sua vigência ser de apenas 4 anos, até ser substituída pela Lei $\mathrm{n}$. $11.343 / 2006$.

Uma das maiores provas da incompetência do legislador nesse caso foi o veto presidencial integral de seu capítulo III, que versava sobre os crimes e as penas. Coincidentemente, o Presidente à época era Fernando Henrique Cardoso, um dos atuais expoentes do pensamento brasileiro em busca da legalização das drogas.

O projeto de lei original trazia que, à posse de drogas para consumo próprio poderia ser punida das seguintes formas:

"Art. 21. As medidas aplicáveis são as seguintes:

I - prestação de serviços à comunidade; 
II - internação e tratamento para usuários e dependentes de produtos, substâncias ou drogas ilícitas, em regime ambulatorial ou em estabelecimento hospitalar ou psiquiátrico;

III - comparecimento a programa de reeducação, curso ou atendimento psicológico;

IV - suspensão temporária da habilitação para conduzir qualquer espécie de veículo;

V - cassação de licença para dirigir veículos;

VI - cassação de licença para porte de arma;

VII - multa;

VIII - interdição judicial;

IX - suspensão da licença para exercer função ou profissão.

$\S 1$ o Ao aplicar as medidas previstas neste artigo, cumulativamente ou não, o juiz considerará a natureza e gravidade do delito, a capacidade de autodeterminação do agente, a sua periculosidade e os fatores referidos no art. 25.

§ 2 o Para determinar se a droga destinava-se a uso pessoal e formar sua convicção, no âmbito de sua competência, o juiz, ou a autoridade policial, considerará todas as circunstâncias e, se necessário, determinará a realização de exame de dependência toxicológica e outras perícias" (BRASIL, 2002a).

Como pode-se perceber, a lei, em sua proposta original, oferecia a possibilidade de internação compulsória do dependente de drogas, além de não possuir limitações quanto ao tempo de tratamento deste. Então, em seu veto do dispositivo, o veto arrazoou que

“O projeto, lamentavelmente, deixou de fixar normas precisas quanto a limites e condições das penas cominadas. Diferentemente do que ocorre nos casos de conversão de penas restritivas de liberdade em restritivas de direitos e vice-versa, o projeto não contém limites temporais expressos que atendam aos princípios constitucionais.

Em matéria tão sensível, não se deve presumir a prudência das instituições, pois a indeterminação da lei penal pode ser a porta pela qual se introduzem formas variadas e cruéis de criminalidade legalizada.

A inconstitucionalidade apontada contamina os artigos 19 e 20, na medida em que estes descrevem tipos penais cujas penas são as presentes no art. 21" (BRASIL, 2002b) (destaque nosso).

Quanto ao delito de tráfico de drogas, tentou-se acrescentar mais dois verbos ao tipo, quais sejam "traficar ilicitamente" e "financiar", totalizando 20 verbos ao tipo penal de tráfico de drogas. Em que pese o legislador ter acreditado na hipótese de recrudescimento da "cruzada contra as drogas", no veto, o Presidente entendeu que

"O verbo "traficar" acrescentado pelo projeto, e que não aparece na lei vigente, poderia concentrar sobre si, em caráter exclusivo, a aplicação da Lei no 8.072, de 25 de julho de 1990 (Crimes Hediondos), que impõe o cumprimento integral em regime fechado da pena para o crime de tráfico ilícito de entorpecentes e drogas afins. Em decorrência disso, apenados condenados por decisão judicial que contenha referência expressa a 
verbos como "produzir", "ter em depósito", por exemplo, não estariam submetidos à norma especial sobre o regime" (BRASIL, 2002b).

Houve também uma série de vetos no que concerne ao rito processual do tráfico de drogas, sendo um dos mais marcantes o que versava sobre a decisão de prisão cautelar do indiciado, que seria pela "garantia da ordem pública, ou para assegurar a aplicação da lei penal" (BRASIL, 2002b).

Entretanto, o veto de tal artigo foi justificado com a alegação de que o art. 312 do Código de Processo Penal dispunha "que a prisão preventiva poderá ser decretada como garantia da ordem pública, da ordem econômica, por conveniência da instrução criminal ou para assegurar a aplicação da lei penal, quando houver prova da existência do crime e indício suficiente de autoria", enquanto que "o projeto restringe as hipóteses previstas no ordenamento codificado. O expurgo da possibilidade de decretação de prisão preventiva por conveniência da instrução criminal constitui grave ofensa ao interesse público" (BRASIL, 2002b).

Aqui, evidenciou-se novamente a inabilidade do legislador, que em uma nova busca de ter um utópico controle social pleno, tentou dispor sobre a liberdade e capacidade dos usuários, além da busca por uma maior criminalização de condutas abstratas, por meio da inclusão de mais verbos nucleares no tipo de tráfico de drogas.

Enfim, chega-se à legislação vigente no momento. A Lei n. 11.343, de 23 de agosto de 2006, teve seu projeto apresentado em 21 de agosto de 2002 - menos de 1 ano depois da lei antidrogas anterior entrar em vigor. Foi assinada pelo Senador Ramez Tebet, presidente do Senado à época, e de autoria da Comissão Mista de Segurança Pública.

Interessante ressaltar que durante sua tramitação foram apensados à ela o PL n. 6.108/2002 e o PL n. 7.134/2002, e foi constatado que nenhum destes projetos lograram êxito em diferenciar a figura do usuário e a do traficante, e a segunda ainda previa "medidas, o tratamento e a internação compulsórios" (COMISSÃO DE CONSTITUIÇÃO E JUSTIÇA E DE REDAÇÃO, 2002, p. 2) aos dependentes.

O próprio relator do PL na Câmara dos Deputados, Paulo Pimenta (PT/RS) afirmou que considera "ter registrada uma abordagem mais atualizada quanto aos aspectos científicos, mais humana, mais democrática, sintonizada com a realidade brasileira e com possibilidades concretas 
de ser implementada" (COMISSÃO DE CONSTITUIÇÃO E JUSTIÇA E DE REDAÇÃO, 2002, p. 6) em relação aos projetos anteriores e à Lei n. 6.368/1976.

Outra situação muito intrigante foi que, em um parecer às emendas de plenário, ocorrido em 11 de fevereiro de 2004, o relator, Dep. Paulo Pimenta, pronunciou que "Chegamos a pensar e alguns Srs. Deputados pensam assim que poderíamos, talvez, já neste momento, iniciar uma discussão sobre a descriminalização do uso de drogas no País" (COMISSÃO DE CONSTITUIÇÃO E JUSTIÇA E DE REDAÇÃO, 2002, p. 1).

Entretanto, mesmo com as diversas evoluções em relação ao tratamento do usuário, bem como a melhor estruturação do SISNAD, ainda ocorreu a majoração da pena mínima do crime de tráfico de drogas para 5 anos, ou seja, dois anos a mais que a lei anterior.

Por fim, curioso o fato de que a exposição de motivos da referida lei tenha sido assinada pelos Deputados Magno Malta e Wanderley Martins (CÂMARA DOS DEPUTADOS, 2002). O primeiro, que seguiu carreira política, se elegendo senador, é uma figura muito conhecida, não tanto por sua atuação parlamentar quanto pelo fato de ser pastor evangélico popular nas redes sociais, que se utilizou do discurso de "cruzada às drogas" para se eleger, autointitulado "ex usuário de drogas" - vide página pessoal do Senador" (MAGNO MALTA, 2019). O segundo, por sua vez, teve trilha política curta, ficou conhecido pelo seu suposto envolvimento com organizações criminosas durante sua campanha (TORRES, 1998), e posteriormente, por seu afastamento da CPI do Narcotráfico em 22 de março de 2000, após a divulgação da informação de que seu ex-assessor e agente da Polícia Federal, Luís Benício Ramos Brivat, teria participado de um esquema de extorsão contra o famoso traficante Fernandinho Beira-Mar (DIÁRIO DO GRANDE ABC, 2000).

Recentemente, veio a Lei n. 13.840, de 5 de junho de 2019, chamada de Lei da Internação compulsória, que a despeito de todas as inovações trazidas como formas de inserção "social e econômica do usuário ou dependentes de drogas" (art. $8^{\circ}$-D, VIII), que infelizmente fora vetada pelo Presidente da República, tornou possível a internação compulsória, sendo esta "aquela que se dá, sem o consentimento do dependente, a pedido de familiar ou do responsável legal ou, na absoluta falta deste, de servidor público da área de saúde, da assistência social ou dos órgãos públicos integrantes do Sisnad, com exceção de servidores da área de segurança pública, que 
constate a existência de motivos que justifiquem a medida" - art. 23-A, $\S 3^{\circ}$, II - (BRASIL, 2019b).

Também estava prevista alteração nas causas de atenuação da pena dos tipos penais previstos no art. 33, caput, e $\S 1^{\circ}$, da Lei n. 11.343/2006, quando "o agente não for reincidente e não integrar organização criminosa"; ou "as circunstâncias do fato e a quantidade de droga apreendida demonstrarem o menor potencial lesivo da conduta" (art. $33, \S 4^{\circ}$, incisos I e II), porém fora vetada com a escusa de "que se coloca em descompasso com as finalidades da reprimenda penal e com os princípios da lesividade e da proibição da proteção deficiente" (BRASIL, 2019a).

Voltando agora à análise do processo legislativo. O autor desse PL foi o Deputado Federal Osmar Gasparini Terra, que o apresentou em 14.07.2010 à Câmara de Deputados. Esse mesmo Deputado, com sucessivas reeleições até o presente momento, licenciou-se em 2017 para exercer o cargo de Ministro do Desenvolvimento Social, e em 2019 para assumir o cargo de Ministro de Estado da Cidadania (CÂMARA DOS DEPUTADOS, 2020). Esse deputado, em uma de suas redes sociais, publicou sobre a existência de uma epidemia de drogas no Brasil, acusando a Fundação Oswaldo Cruz - FIOCRUZ - de negar tal fato em vista de outros interesses.

Osmar Terra ainda foi responsável pelo embargo da divulgação do III Levantamento Nacional sobre o Uso de Drogas pela população brasileira. Pesquisa essa encomendada pela Secretaria Nacional de Políticas sobre Drogas do Ministério da Justiça e Segurança Pública (SENAD/MJSP) à FIOCRUZ e que estava finalizada desde 2017, mas que só pôde ser divulgada após intervenção da Advocacia Geral da União - AGU - nas negociatas (AGU, 2019; SAYURI, 2019; e TWITTER, 2019).

Tal pesquisa mostrou resultados contrários aos comentários de Osmar Terra, tanto em relação à existência de epidemia, quanto ao fato de o álcool causar mais danos sociais e econômicos que todas as outras drogas ilícitas (FIOCRUZ, SENAD; 2017, p. 150/162).

Por derradeiro, temos a Lei Federal no 13.694, de 24 de dezembro de 2019, intitulada de Pacote Anticrime, que trouxe acréscimo ao art. $33, \S 1^{\circ}$, IV, da Lei de Drogas, incluindo no tipo penal de tráfico, a conduta de quem "vende ou entrega drogas ou matéria-prima, insumo ou produto químico destinado à preparação de drogas, sem autorização ou em desacordo com a 
determinação legal ou regulamentar, a agente policial disfarçado, quando presentes elementos probatórios razoáveis de conduta criminal preexistente" (BRASIL, 2019c).

Detalhe é que o STF, em 13.12.1963, editou a Súmula 145, dizendo que "Não há crime, quando a preparação do flagrante pela polícia torna impossível a sua consumação” (STF, 1963).

Tal ampliação do tipo penal do tráfico de drogas surge pelo pretexto da "evidente necessidade de serem criados novos instrumentos de investigação voltados para prevenção de delitos praticados por organizações criminosas, com modificações na Lei 12.850/2013”, já que até o enrijecimento do tratamento do comércio ilegal de armas tem o "objetivo de reprimir de forma mais adequada os delitos de extrema gravidade, praticados no âmbito de organizações criminosas, notadamente aquelas envolvidas no tráfico de drogas", sendo assim, o tráfico de drogas eleito o culpado pela maioria dos delitos graves na sociedade, conforme justificação do Projeto de Lei 10372/2018 (CÂMARA DOS DEPUTADOS, 2018, p. 33/34).

\section{0 retorno de políticas arcaicas}

Por todas as legislações expostas, percebe-se que as redações destas se tornaram mais precisas, e mais duras. Talvez o maior domínio das técnicas de redação ao longo do tempo, permitiu, inclusive, um drible nas questões de direito material.

Isso é mais visível quando analisamos o retorno da figura da internação compulsória, que parecia ter sido findada na lei de 2002, mas só estava adormecida. Trazemos à baila alguns projetos de lei sobre a temática, posteriores à 2002, tendo um deles resultado na Lei n. 13.840/2019.

O primeiro exemplo é de 14.09.2011, quando foram rejeitados, no bojo dos PL n. 7663/2010 (Lei n. 13.840/2019), os PLs n. 888/11, 1.144/11, 1.905/11 e 1.931/11, que traziam em suas redações o instituto da internação compulsória (CÂMARA DOS DEPUTADOS, 2019). Posteriormente, temos os PLs n. 2.372/11, 3.167/12, 3.365/12 e 3.450/12, que foram apensados como substitutivos, em 28.11.2012, também tratando da internação (CÂMARA DOS DEPUTADOS, 2019).

Em 29.11.2012, foi negado o apensamento do PL n. 4.312/2008, que modificava a Lei n. 10.216/2001, e tratava sobre a internação compulsória. Atente-se que essa lei de 2001 não fora revogada expressamente.

\footnotetext{
Rev. de Criminologias e Políticas Criminais | e-ISSN: 2526-0065 | Evento Virtual | v. 6 | n. 1 | 
Por fim, indicamos o Projeto de Lei n. 285, de 2018, da Senadora Rose de Freitas, do partido PODEMOS/ES, trazendo novamente a figura da internação compulsória (SENADO FEDERAL, 2018), mesmo durante a tramitação de inúmeros projetos de lei tratando da temática.

Assim, mostra-se evidente a incapacidade de trabalhos sistematizados pelos legisladores, e a utilização de projetos de lei como ferramenta política, considerando que o assessoramento das câmaras legislativas podem encontrar facilmente outros projetos de lei que tratem da mesma temática, mesmo antes do início da tramitação, não havendo, portanto, justificativas para PLs com assunto repetido.

\section{CONSIDERAÇÕES FINAIS}

Da análise das legislações supracitadas, pode se inferir que a política criminal de drogas no Brasil teve algumas fases marcantes.

A primeira se caracteriza como uma colcha de retalhos, sendo copiada do Direito Penal Português, que deu origem ao Código Penal de 1890.

A segunda acompanhou os Tratados Internacionais, que nada mais foi do que as imposições dos Estados Unidos da América ao resto dos países signatários da Liga das Nações, e posteriormente, Organização das Nações Unidas, do período de 1921 à 1967.

A terceira foi de 1968 até a promulgação da Constituição Federal de 1988, sendo esse o período de maior transformação nas políticas de drogas, principalmente pelo fato de a Ditadura Militar utilizar-se dessa política para legitimar a caçada das resistências.

Por fim, a quarta daria conta das legislações pós constitucionais, que foram elaboradas sob a égide de legisladores eleitos, mas mesmo assim não apresentaram melhoras em detrimento das legislações ditatoriais, e que está caminhando novamente para o recrudescimento excessivo.

Ante ao exposto, tem-se que, mesmo frente a um novo pensamento social, o objetivo moralizante da legislação criminal de drogas ainda se faz muito presente. Nota-se também que, para a manutenção da criminalização da conduta de drogas, pode-se passar por cima de diversos requisitos elementares de uma legislação sancionatória, desde a imparcialidade explícita do legislador que se afigura como componente básico da validade da legislação, bem como a falta de análise da proporcionalidade das penas, da pragmaticidade dos efeitos da lei na sociedade, e da ausência de participação pública no ato legislativo. Enfim, observa-se que, conforme os governos

Rev. de Criminologias e Políticas Criminais | e-ISSN: 2526-0065 | Evento Virtual | v. 6 | n. 1 | 
tornam-se mais autoritários, a privação de liberdades individuais - nesse caso, na figura da internação compulsória - aumenta.

\section{REFERÊNCIAS BIBLIOGRÁFICAS}

AGU. Nota à Imprensa. Disponível em: http://www.agu.gov.br/page/content/detail/id_conteudo/789618. Acesso em: 06 de abr. de 2020. ASSEMBLÉIA NACIONAL CONSTITUINTE. 1 - COMISSÃO DA SOBERANIA E DOS DIREITOS E GARANTIAS DO HOMEM E DAMULHER. 1-c - SUBCOMISSÃO DOS DIREITOS E GARANTIAS INDIVIDUAIS. RELATÓRIO. Vol. 78, de 11 de maio de 1987. Disponível em: https:/www.camara.leg.br/internet/constituicao20anos/DocumentosAvulsos/vol78.pdf. Acesso em: 06 de abr. de 2020.

ASSEMBLÉIA NACIONAL CONSTITUINTE. CONSTITUINTE FASE B. EMENDAS AO ANTE-PROJETO DO RELATOR DA SUBCOMISSÃO. Vol. 79, 1987b. Disponível em: https://www.camara.leg.br/internet/constituicao20anos/DocumentosAvulsos/vol-79.pdf. Acesso em: 06 de abr. de 2020.

ASSEMBLÉIA NACIONAL CONSTITUINTE. EMENDAS OFERECIDAS AO SUBSTITUTO. I - Comissão da Soberania e dos Direitos e Garantias do Homem e da Mulher. Vol. 67, 1987c. Disponível em: https://www.camara.leg.br/internet/constituicao20anos/DocumentosAvulsos/vol-67.pdf. Acesso em: 06 de abr. de 2020.

BECKER, Howard Saul. Outsiders: Estudos de sociologia do desvio. 1. Ed. Rio de Janeiro: Jorge Zahar Editor, 2008.

BRASIL (Vicente Piragibe). Consolidação das Leis Penaes (Decreto n. 22.213/1932b). Aprova a Consolidação das Leis Penais, da autoria do Sr. Desembargador Vicente Piragibe. Disponível em: http://www.planalto.gov.br/ccivil_03/decreto/1930-1949/D22213.htm. Acesso em: 05 de abr. de 2020.

BRASIL. Constituição Da República Federativa Do Brasil De 1988. Disponível em: http://www.planalto.gov.br/ccivil_03/Constituicao/Constituicao.htm. Acesso em: 05 de abr. de 2020.

BRASIL. Decreto n⿳ 154, de 26 de junho de 1991. Promulga a Convenção Contra o Tráfico Ilícito de Entorpecentes e Substâncias Psicotrópicas. Disponível em: http://www.planalto.gov.br/ccivil_03/decreto/1990-1994/d0154.htm. Acesso em: 05 de abr. de 2020.

BRASIL. Decreto no 20.930, de 11 de janeiro de 1932a. Fiscaliza o emprego e o comércio das substâncias tóxicas entorpecentes, regula a sua entrada no país de acordo com a solicitação do Comité Central Permanente do Opio da Liga das Nações, e estabele penas. Disponível em: http://www2.camara.leg.br/legin/fed/decret/1930-1939/decreto-20930-11-janeiro-1932-498374publicacaooriginal-81616-pe.html. Acesso em: 05 de abr. de 2020. 
BRASIL. Decreto n' 4.294, de 6 de julho de 1921. Estabelece penalidades para os contraventores na venda de cocaina, opio, morphina e seus derivados; crêa um estabelecimento especial para internação dos intoxicados pelo alcool ou substancias venenosas; estabelece as fórmas de processo e julgamento e manda abrir os creditos necessários. Disponível em: http://www2.camara.leg.br/legin/fed/decret/1920-1929/decreto-4294-6-julho-1921-569300republicacao-92584-pl.html. Acesso em: 05 de abr. de 2020.

BRASIL. Decreto n' 54.216, de 27 de agosto de 1964. Promulga a Convenção Única sobre Entorpecentes. Disponível em: http://www2.camara.leg.br/legin/fed/decret/1960-1969/decreto54216-27-agosto-1964-394342-publicacaooriginal-1-pe.html. Acesso em: 05 de abr. de 2020.

BRASIL. Decreto no 79.388, de 14 de março de 1977. Promulga a Convenção sobre Substâncias Psicotrópicas. Disponível em: http://www2.camara.leg.br/legin/fed/decret/1970-1979/decreto79388-14-marco-1977-428455-publicacaooriginal-1-pe.html. Acesso em: 05 de abr. de 2020.

BRASIL. Decreto no 847, de 11 de outubro de 1890. Promulga o Codigo Penal. Disponível em: http://www.planalto.gov.br/ccivil_03/decreto/1851-1899/d847.htm. Acesso em: 06 de abr. de 2020.

BRASIL. Decreto-lei no 159, de 10 de fevereiro de 1967. Dispõe sôbre as substâncias capazes de determinar dependência física ou psíquica, e dá outras providências. Disponível em: http://www2.camara.leg.br/legin/fed/declei/1960-1969/decreto-lei-159-10-fevereiro-1967373406-publicacaooriginal-1-pe.html. Acesso em: 05 de abr. de 2020.

BRASIL. Decreto-lei no 385, de 26 de dezembro de 1968. Dá nova redação ao artigo 281 do Código Penal. Disponível em: http://www.planalto.gov.br/ccivil_03/decreto-lei/19651988/Del0385.htm. Acesso em: 05 de abr. de 2020.

BRASIL. Lei $\mathbf{n}^{\mathbf{0}} \mathbf{1 0 . 4 0 9}$, de 11 de janeiro de 2002a. Dispõe sobre a prevenção, o tratamento, a fiscalização, o controle e a repressão à produção, ao uso e ao tráfico ilícitos de produtos, substâncias ou drogas ilícitas que causem dependência física ou psíquica, assim elencados pelo Ministério da Saúde, e dá outras providências. Disponível em: http://www.planalto.gov.br/ccivil_03/LEIS/2002/L10409.htm. Acesso em: 05 de abr. de 2020.

BRASIL. Lei $\mathbf{n}^{\mathbf{0}}$ 11.343, de 23 de agosto de 2006. Institui o Sistema Nacional de Políticas Públicas sobre Drogas - Sisnad; prescreve medidas para prevenção do uso indevido, atenção e reinserção social de usuários e dependentes de drogas; estabelece normas para repressão à produção não autorizada e ao tráfico ilícito de drogas; define crimes e dá outras providências. Disponível em: http://www.planalto.gov.br/ccivil_03/_ato2004-2006/2006/lei/111343.htm. Acesso em: 05 de abr. de 2020.

BRASIL. Lei no 13.840, de 5 de junho de 2019b. Altera as Leis nos 11.343, de 23 de agosto de 2006, 7.560, de 19 de dezembro de 1986, 9.250, de 26 de dezembro de 1995, 9.532, de 10 de dezembro de 1997, 8.981, de 20 de janeiro de 1995, 8.315, de 23 de dezembro de 1991, 8.706, de 14 de setembro de 1993, 8.069, de 13 de julho de 1990, 9.394, de 20 de dezembro de 1996, e 9.503, de 23 de setembro de 1997, os Decretos-Lei nos 4.048, de 22 de janeiro de 1942, 8.621, de 10 de janeiro de 1946 , e 5.452, de $1^{\circ}$ de maio de 1943, para dispor sobre o Sistema Nacional de Políticas Públicas sobre Drogas e as condições de atenção aos usuários ou dependentes de drogas e para tratar do financiamento das políticas sobre drogas. Disponível em: 
http://www.planalto.gov.br/ccivil_03/_Ato2019-2022/2019/Lei/L13840.htm. Acesso em: 05 de abr. de 2020. Acesso em: 05 de abr. de 2020.

BRASIL. Lei no 13.964, de 24 de dezembro de 2019c. Aperfeiçoa a legislação penal e processual penal. Disponível em: http://www.planalto.gov.br/ccivil_03/_Ato20192022/2019/Lei/L13964.htm. Acesso em: 05 de abr. de 2020.

BRASIL. Lei no 4.451, de 4 de novembro de 1964. Altera a redação do artigo 281 do Código Penal. Disponível em: http://www.planalto.gov.br/ccivil_03/LEIS/1950-1969/L4451.htm. Acesso em: 05 de abr. de 2020.

BRASIL. Lei no 5.726, de 29 de outubro de 1971. Dispõe sôbre medidas preventivas e repressivas ao tráfico e uso de substâncias entorpecentes ou que determinem dependência física ou psíquica e dá outras providências. Disponível em: http://www.planalto.gov.br/ccivil_03/LEIS/1970-1979/L5726.htmimpressao.htm. Acesso em: 05 de abr. de 2020.

BRASIL. Lei no 6.368, de 21 de outubro de 1976. Dispõe sobre medidas de prevenção e repressão ao tráfico ilícito e uso indevido de substâncias entorpecentes ou que determinem dependência física ou psíquica, e dá outras providências. Disponível em: http://www.planalto.gov.br/ccivil_03/LEIS/L6368.htmimpressao.htm. Acesso em: 05 de abr. de 2020.

BRASIL. Mensagem no 239, de 5 de junho de 2019a. Disponível em: http://www.planalto.gov.br/ccivil_03/_Ato2019-2022/2019/Msg/VEP/VEP-239.htm. Acesso em: 05 de abr. de 2020. Acesso em: 05 de abr. de 2020.

BRASIL. Mensagem $\mathbf{n}^{\mathbf{0}}$ 25, de 11 de janeiro de 2002b. Disponível em: http://www.planalto.gov.br/ccivil_03/LEIS/Mensagem_Veto/2002/Mv025-02.htm. Acesso em: 06 de abr. de 2020.

CÂMARA DOS DEPUTADOS (BRASIL). INTEIRO TEOR DO PL 10372/2018. Disponível em:

https://www.camara.leg.br/proposicoesWeb/prop_mostrarintegra?codteor $=1666497 \&$ filename $=\mathrm{P}$ L+10372/2018. Acesso em: 05 de abr. de 2020.

CÂMARA DOS DEPUTADOS (BRASIL). Legislação Informatizada - LEI No 11.343, DE 23 DE AGOSTO DE 2006 - Exposição de Motivos, 07 de mai. de 2002. Disponível em: https://www2.camara.leg.br/legin/fed/lei/2006/lei-11343-23-agosto-2006-545399-

exposicaodemotivos-150201-pl.html. Acesso em: 06 de abr. de 2020.

CÂMARA DOS DEPUTADOS (BRASIL). OSMAR TERRA. Disponível em: https://www.camara.leg.br/deputados/73692/biografia. Acesso em: 05 de abr. de 2020.

CÂMARA DOS DEPUTADOS (BRASIL). PL 7663/2010. 5 de junho de 2019. Disponível em: https://www.camara.leg.br/proposicoesWeb/fichadetramitacao?idProposicao=483808. Acesso em: 05 de abr. de 2020. 
CARVAlHO, Érika Mendes de; ÁVILA, Gustavo Noronha de. Falsos Bens Jurídicos e Política Criminal de Drogas: Uma Aproximação Crítica. Conpedi Law Review, v. 1, n. 10, p. 132-155, 2016.

COMISSÃO DE CONSTITUIÇÃO E JUSTIÇA E DE REDAÇÃO (BRASIL). PROJETO DE LEI $\quad \mathrm{N}^{\circ} \quad 7.134, \quad \mathrm{DE} \quad 2002 . \quad$ Disponível em: https://www.camara.leg.br/proposicoesWeb/prop_mostrarintegra?codteor $=197758 \&$ filename $=P R$ L+1+CCJC+\%3D\%3E+PL+7134/2002. Acesso em: 06 de abr. de 2020.

Conselho Nacional de Justiça - CNJ; Banco Nacional de Monitoramento de Prisões - BNMP. Cadastro Nacional de Presos. Brasília, agosto de 2018. Disponível em: https://www.cnj.jus.br/wp-content/uploads/2018/01/57412abdb54eba909b3e1819fc4c3ef4.pdf. Acesso em: 04 de abr. de 2020.

D’ELIA FILHO, Orlando Zaccone. Acionistas do nada: quem são os traficantes de drogas. 3. Ed. Rio de Janeiro: Revan, 2011.

DIÁRIO DO GRANDE ABC. Seção Política. Wanderley Martins se afasta da CPI do Narcotráfico. Santo André, 22 de mar. de 2000. Disponível em: https://www.dgabc.com.br/Noticia/221254/wanderley-martins-se-afasta-da-cpi-do-narcotrafico. Acesso em: 06 de abr. de 2020.

Fundação Oswaldo Cruz - FIOCRUZ; Secretaria Nacional de Políticas sobre Drogas - SENAD. III Levantamento Nacional Domiciliar sobre o Uso de Drogas. 2017. Disponível em:

MAGNO MALTA. Usei drogas mas Jesus me salvou. Disponível em: http://magnomalta.com/index.php/outras-notas-mainmenu-45/1581-usei-drogas-mas-jesus-mesalvou. Acesso em: 06 de abr. de 2019.

RAMOS, João Gualberto Garcez. A inconstitucionalidade do "Direito Penal do Terror". Textos selecionados: v. 3. Curitiba: Juruá, 1991.

SAYURI, Juliana. O embargo de um estudo inédito da Fiocruz sobre drogas. NEXO, São Paulo, 28 de mai. de 2020. Disponível em: https://www.nexojornal.com.br/expresso/2019/05/28/O-embargo-de-um-estudo-in\%C3\%A9ditoda-Fiocruz-sobre-drogas. Acesso em: 06 de abr. de 2020.

SENADO FEDERAL (BRASIL). Projeto de Lei do Senado $\mathbf{n}^{\circ}$ 285, de 2018. Disponível em: https://www25.senado.leg.br/web/atividade/materias/-/materia/133608. Acesso em: 11 de abr. de 2020.

STF. Súmula 145, de 13 de dez. de 1963. Disponível em: http://www.stf.jus.br/portal/jurisprudencia/listarJurisprudencia.asp?s1=145.NUME.\%20NAO\%2 0S.FLSV.\&base=baseSumulas. Acesso em: 07 de abr. de 2020.

TERRA, Osmar. O que você acha? 56 milhões de brasileiros(27\% da população) tem um parente próximo viciado em drogas, segundo pesquisa Datafolha publicada ontem !!!! E a Fiocruz insiste em dizer que não existe epidemia de drogas no Brasil... Porto Alegre, 11 jul. 2019. Disponível em: https://twitter.com/OsmarTerra/status/1149286399675457537. Acesso em: 06 de abr. de 2020. 
TORRES, Sergio. Delegados suspeitos são candidatos no RJ. FOLHA DE SÃO PAULO, São Paulo, 12 de jul. de 1998. Disponível em: https://www1.folha.uol.com.br/fsp/brasil/fc12079821.htm. Acesso em: 06 de abr. de 2020.

VALOIS, Luís Carlos. O Direito Penal da Guerra às Drogas. 2. Ed. Belo Horizonte: D’Plácido, 2017.

ZAFFARONI, Eugenio Raúl; PIERANGELI, José Henrique. Manual de Direito Penal Brasileiro: parte geral. 4. Ed. rev. São Paulo: Revista dos Tribunais, 2002. 